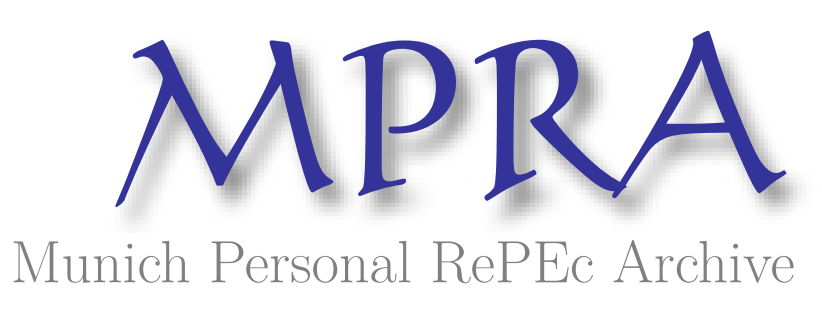

\title{
Deterrence effects under Twombly: on the costs of increasing pleading standards in litigation
}

Campos, Sergio and Cotton, Christopher and Li, Cheng

University of Miami, Queen's University, Mississippi State University

May 2015

Online at https://mpra.ub.uni-muenchen.de/65604/

MPRA Paper No. 65604, posted 16 Jul 2015 16:32 UTC 


\title{
DETERRENCE EFFECTS UNDER TWOMBLY: ON THE COSTS OF INCREASING PLEADING STANDARDS IN LITIGATION
}

\author{
SERGIO J. CAMPOS, CHRISTOPHER COTTON, AND CHENG LI
}

\begin{abstract}
Aвstract. We develop a stylized game theoretic model of litigant behavior to study the effects of increased pleading standards on incentives to engage in illegal activity. Such a model is necessary to build intuition about the potential costs associated with the procedures set forth by the U.S. Supreme Court in Bell Atlantic Corp. v. Twombly (550 U.S. 544 [2007]) and Ashcroft v. Iqbal (556 U.S. 662, 684 [2009]), which increase the standard of plausibility that lawsuits must meet before being allowed by a judge to proceed to discovery and trial. We show how increasing pleading standards tends to increase illegal activity, and can increase litigation costs. These negative effects should be accounted for when setting a pleading standard. Our results provide a counterpoint to the U.S. Supreme Court's argument that increased plausibility requirements will decrease the costs of litigation.
\end{abstract}

Date: Current version: May 2015.

Key words and phrases. Judicial procedure, pleading, litigation, deterrence JEL: C72, K41.

Campos: University of Miami Law School, 1311 Miller Drive, Coral Gables, FL 33146; scampos@law.miami.edu. Cotton: Queen's University, Department of Economics, 94 University Avenue, Kingston, Ontario K7L 3N6; cotton@econ.queensu.ca. Li: Mississippi State University, Department of Finance and Economics, 40 Old Main, Mississippi State, MS 39762; cheng.li@msstate.edu. We appreciate feedback from Louis Kaplow, David Rosenberg, Kathy Spier, Joshua Teitelbaum and seminar participants at DePaul University College of Law, Georgetown Law School and the University of Miami Law School. Many thanks to Andrew Beaulieu and Alexandra Hayes for their research assistance. Cotton is grateful for financial support provided through his position as the JarislowskyDeutsch Chair in Economic and Financial Policy at Queen's University. 


\section{INTRODUCTION}

Federal courts in the United States have recently expressed concern about the high costs of litigation for defendants, particularly the costs of discovery. ${ }^{1}$ Because of the "American rule," which makes the parties responsible for their own litigation costs (Rowe 1982), defendants may incur great costs in litigation even when they are not liable.

In a recent antitrust case, Bell Atlantic Corp. v. Twombly (550 U.S. 544, 570 [2007]), the U.S. Supreme Court addressed this concern by increasing the pleading standard, permitting a defendant to seek dismissal of a lawsuit before discovery if the plaintiff fails to allege a "plausible" claim. The Court rejected prior case law which permitted suits to proceed to discovery and trial if the facts alleged were "merely consistent with" an entitlement to recovery. The Court emphasized that a "plausibility" standard is necessary because the implausibility of a claim should "be exposed at the point of minimum expenditure to time and money by the parties and the court." ${ }^{2}$ In a later case, Ashcroft v. Iqbal (556 U.S. 662, 684 [2009]), the Court made clear that this new pleading standard applies to all cases.

The Court's concerns in Twombly and Iqbal have spurred voluminous legal scholarship (see Reinert 2012). However, the literature has focused almost exclusively on their effects on lawsuits already filed in federal court (Engstrom 2013, Kaplow 2013). In contrast, we examine the effects of the stronger pleading standards implemented by Twombly and Iqbal on the defendant's incentives to engage in unlawful conduct in the first place.

A potential defendant's decision to engage in conduct which may harm another party depends on the likelihood that the defendant's action causes harm, and the probability an injured party sues, obtains discovery and proves the claim in court. Twombly and Iqbal change the pleading standard and therefore change the likelihood of obtaining discovery and proceeding to trial. In this way, the Supreme Court ruling affects the incentives potential defendants have for taking potentially harmful actions in the first place. The impact of pleading standards on deterrence has largely been overlooked by the literature. Ours is one of only a few papers that focus on the effect of the Supreme Court's decision on deterrence.

We develop a game theoretic model of litigant behavior to study the effects of stronger pleading standards on the primary behavior of potential defendants. Using intuitive assumptions, our analysis considers how an increase in pleading standards

\footnotetext{
${ }^{1}$ Discovery is a phase of litigation that allows the parties to compel the disclosure of evidence from each other and from third parties. It is costly because the parties incur the costs of providing requested information to the other side. For example, a party is permitted to request documents or other tangible things from another party (Fed. R. Civ. P. 34). Typically a request for documents requires a party to incur extensive search costs (e.g., looking through file cabinets and warehouses, searching through electronic databases), production costs (e.g., making paper copies of the documents, subjecting the copies to review by attorneys for redaction of privileged matters), and distribution costs (e.g., shipping the documents to the requesting party). Similar costs arise for depositions (Fed. R. P. 30), which allow the parties to compel the oral testimony of witnesses under oath.

${ }^{2}$ Twombly at 557 and 558.
} 
affects deterrence, and how its effect on deterrence may influence litigation accuracy and total litigation costs. Our paper is not intended as a thorough welfare analysis or to determine the optimal pleading standard, which would require a broader consideration of all potential costs and benefits of the procedure change. ${ }^{3}$ Rather, our focus is on deterrence. Our model is simple, intended to maximize intuition about how pleading standards influence incentives to engage in illegal activity, a cost of raising the pleading standard which has largely been overlooked in the literature.

The analysis determines how a potential defendant's incentives to engage in an illegal activity depends on the pleading standard. The equilibrium probability with which the defendant takes the illegal action influences the likelihood the plaintiff wins a suit that makes it to trial. In equilibrium, the defendant takes the unlawful action neither so infrequently that it would never be rational for the plaintiff to sue, nor so frequently that the plaintiff and judge always expect that he is liable. Rather, he plays a mixed strategy. The defendant takes the unlawful action just often enough to leave the judge indifferent between trying or dismissing a case. ${ }^{4}$ The probability that the judge dismisses a case increases as the pleading standard rises. The defendant recognizes this, and in response to the higher pleading standard, he chooses the unlawful action more often. ${ }^{5}$

When deterrence decreases, potential defendants engage in illegal activities more often, and the total amount of litigation increases. In this way, increasing pleading standards can increase total litigation costs. This result works against the standard argument in favor of higher pleading standards, as put forth by the Supreme Court and throughout the literature. The majority in Twombly, for example, emphasized that "it is only by taking care to require allegations that reach the level [of plausibility] that we can hope to avoid the potentially enormous expense of discovery in cases with no reasonably founded hope that the [discovery] process will reveal relevant evidence to support [the] claim." (Twombly, 550 U.S. at 559-60). We show that raising pleading standards does not necessarily reduce the expense of litigation. Through its effect on deterrence, increasing pleading standards increase the total costs of litigation, the exact thing that increasing the standard is intended to decrease. To understand this, note that total litigation costs depend on both the number of injuries and the probability an injury claim proceeds to litigation. We show that with stronger pleading standards, a potential defendant engages in the unlawful activity more often, which results in the plaintiff experiencing harm more often, which can

\footnotetext{
${ }^{3}$ Kaplow (2012) provides such an analysis, which we discuss in the literature review.

${ }^{4}$ The reasoning behind the mixed strategy equilibrium in our model is similar to that regarding the mixed strategy equilibria in Ordover (1978) and Baker and Malani (2014), among others. Our contribution comes from considering how changes to pleading standards may affect equilibrium behavior and outcomes such as total litigation costs. Implicit in these models is an assumption that decision makers are Bayesians, updating their beliefs about potential liability as the rate of equilibrium illegal activity changes. For a discussion of such assumptions, see Friedman and Wickelgren (2006) and Baker and Malani (2014).

${ }^{5} \mathrm{~A}$ similar effect would be caused by anything that increased the standard a case is held to before proceeding to discovery and trial (Kaplow 2013).
} 
lead to an increase in litigation. For similar reasons, judicial screening increases the equilibrium probability that the potential defendant is liable, but does not change the probability that a liable defendant compensates the plaintiff for her injury. This increases the ex ante probability that a defendant harms and does not compensate a plaintiff, decreasing outcome accuracy.

Our results stand in contrast with those from models that do not account for the impact of pleading standards on deterrence, and demonstrate the importance of considering deterrence in an analysis of higher pleading standards. If we took the probability of defendant liability as fixed, then increasing higher pleading standards unambiguously decreases litigation costs. Allowing potential defendants to rationally change their behavior in response to changes in pleading standards reverses the results. When accounting for (negative) deterrence effects, increasing pleading standards tends to increase unlawful activity, resulting in a net increase in litigation costs and a net decrease in litigation accuracy.

One of the primary arguments in favor of increasing pleading standards is that doing so will decrease the prevalence of nuisance suits filed by plaintiffs who sustain no harm with the intent of attracting a settlement. To consider this possibility, Section 6 extends our model to incorporate this feature, and determines under which conditions nuisance suits arise in equilibrium. We show how increasing the pleading standard in this environment continues to decrease deterrence and increase total litigation costs. Thus, our main result from the earlier sections is shown to hold even in the presence of nuisance suits. Increasing pleading standards increases incentives of potential defendants to engage in illegal activity, even when it may decrease the probability of nuisance suits in equilibrium.

An increased pleading standard may also be beneficial if it reduces the "chilling" effects associated with potential defendants taking overly cautious actions from the perspective of social welfare. To consider this possibility, Section 7 extends our model to incorporate the chilling of desirable behavior, and identifies the conditions under which the potential defendant takes an overly cautious action. We show how increasing the pleading standard does not change the potential defendant's incentive to take the overly safe action. Thus, increasing pleading standards does not necessarily have the benefit of reducing chilling effects. We also show how the interaction between pleading standards and deterrence effects which we identify in our main model continues to exist in this alternative model.

Therefore, our main results from the initial analysis continue to hold when we incorporate nuisance suits and chilling effects into the analysis.

We formulate our argument using a stylized model, designed to most effectively convey the intuition behind our results, and illustrate how higher pleading standards decreases deterrence and can push up total litigation costs. Our intention is to isolate the deterrence effect, rather than to derive social welfare or the optimal pleading standard, and therefore it is appropriate to consider the simplest environment for which our results exist. For example, we treat the process of discovery and trial following a judge's decision to permit a case as a black box, assuming only that it imposes costs on litigants and determines a trial outcome. For the same reasons, 
we also abstract from summary judgment, which, like using pleading standards to dismiss a lawsuit, is designed to reduce the costs of litigation. As we discuss in more detail below, we consider summary judgment a part of the black box of litigation because it typically cannot be used to avoid the costs of discovery, and thus does not undermine the assumption used in the model that litigation is costly after the pleading stage. Formally modeling such aspects of litigation would improve the realism of the model, but would also greatly increase the complexity of the analysis without adding to the basic intuition behind our argument. We discuss alternative assumptions in Section 8.

The paper is presented as follows. Section 2 present literature review. Section 3 develops the game theoretic model. Section 4 solves for the equilibrium of the game. Second 5 considers the impact of imposing strictly pleading standards. Section 6 considers an extension of our framework, in which nuisance suits arise in equilibrium. Section 7 considers an extension of the main model that incorporates the chilling of desirable behavior. Section 8 discusses alternative assumptions and Section 9 concludes. The appendix provides formal proofs of our results.

\section{Literature Review}

Twombly and Iqbal have generated a significant amount of scholarship, with at least one scholar finding that, as of 2012, the decision has "been cited by more than 26,000 courts, more than 500 law review articles, and innumerable briefs and motions" (Reinert 2012). Some scholars have expressed support for the new pleading standard (e.g. Anderson and Huffman 2010). Others, however, have argued that the new pleading standards place a significant burden on plaintiffs asserting claims, particularly civil rights claims, and that the standards effectively reduce access to justice (e.g. Spencer 2013, Dodson 2013, Gelbach 2011, Steinman 2010, Miller 2010). Still others argue that the new pleading standards are not new at all, since courts have consistently required "plausibility" by only crediting "reasonable inferences" (e.g Hartnett 2009, Huston 2010). And still others argue that the new pleadings standards should be coupled with revised discovery procedures to avoid access to justice problems (e.g. Fitzpatrick 2012, Dodson 2010).

The economic literature on the deterrence effect of law enforcement is also vast. In his seminal work, Becker (1968) argues that since rational criminals respond to conditions of risks, the probability and the severity of punishment deter crime. Since then, scholars have focused on characterizing the optimal law enforcement system and have extended Becker's model to a variety of aspects of law enforcement. ${ }^{6}$ Friedman and Wickelgren (2006) show how deterring all crime is not feasible unless judges and juries have access to perfect information when assessing the liability of defendants. Previous research also examines the effect of tort reforms on incentives to obey the law and incentives for care. Png (1987) studies the effects of changes in

\footnotetext{
${ }^{6}$ Garoupa (1997) and Polinsky and Shavell (2000) provide excellent surveys of the theory of optimal law enforcement.
} 
court award, negligence standard and the allocation of litigation costs on potential injurer's incentive for care. Hylton $(1990,1993)$ and Wijck and Velthoven (2000) analyze the influence of litigation cost allocation rules on deterrence. Polinsky and Che (1991) examines the effect of reforms in the liability system on incentives for care. Daughety and Reinganum $(2013,2014)$ studies how different liability regimes affect the choice of care by firms when harm is cumulative. Jost (1995) examines the effect of discovery rules on the incentives for accident prevention by potential injurers. Landeo, Nikitin and Baker (2007) studies the effect of punitive damages reforms, such as damage caps and split awards, on deterrence.

The mixed strategy nature of our equilibrium is not unique to our paper. For example, Ordover (1978) argues that a plaintiff will follow a mixed strategy when deciding whether to sue a defendant, as a defendant who is always sued will always have an incentive to avoid doing harm, and a defendant who is never sued will always choose a harmful action. More recently, Baker and Malani (2014) show that similar login carries over to the case of a judge deciding whether to dismiss a case. They consider the relationship between the rate of dismissal and incentives for deterrence. Absent from these analyses is a consideration of how changes to the pleading standard as induced by Twombly and Iqbal alters the equilibrium outcome, including total litigation costs.

Despite the significant scholarship on Twombly and Iqbal, only a few scholars acknowledge the effect of these rulings on the defendant's ex ante behavior. The most closely related paper to ours is the concurrent work of Kaplow (2012), which presents a general game theory model and considers termination of lawsuits at different points during multistage adjudication. Kaplow, like us, allows dismissal standards to influence incentives to take harmful actions in the first place. His impressive analysis focuses on determining the characteristics of optimal dismissal procedures in a general model; but given the generality of the framework, one cannot solve for closed form solutions of equilibrium strategies, or say much about how changes to dismissal standards influence equilibrium behavior away from the social optimum. Our paper, on the other hand, presents a simple, highly-stylized model which focuses primarily on deterrence effects. We are able to derive closed-form solutions for equilibrium strategies, and develop an understanding of how pleading standards influence deterrence, even away from the socially optimal level. Being able to do this is important for considering the impact of the recent Supreme Court rulings, as there is no reason to believe that pleading standards are or were set at the optimal level. Finally, by considering the simplest possible model in which pleading standards influence deterrence, we focus on developing intuition about the deterrence effects, which have generally been overlooked in the literature.

In a law review article, Kaplow (2013) also discusses deterrence effects associated with pleading standards. Others who have pointed out the potential effect of Twombly and Iqbal on deterrence have done so only briefly (Engstrom 2013, Hoffman 2011). Our analysis and Kaplow (2012) are the only articles that we are aware of to analyze these effects within a formal model. 
Many scholars have empirically studied the effect of Twombly and Iqbal (e.g. Engstrom 2013, Gelbach 2011, 2012). However, they have only focused on the effect of the decisions on dismissal rates. Of these scholars, Jonah Gelbach has acknowledged the effect of Twombly and Iqbal on "primary behavior" (Gelbach 2012). But Gelbach only provides some examples of the possible effects of judicial screening on deterrence. $^{7}$

\section{PReliminaries}

3.1. Model. We develop a stylized model simplified to highlight only the aspects of the litigation process which are important for our argument. There are three players: a plaintiff $P$ who may experience harm, a defendant $D$ who may be liable for the harm, and a judge $J$.

The game takes place in four stages:

(1) D decides whether to take an unlawful action that benefits himself, but increases the probability that $P$ suffers a loss. If he takes the unlawful action, he is "liable." Whether P suffers a loss is publicly observable, but whether D is liable is not. If $P$ suffers a loss, regardless of whether $D$ is liable, the game moves on to stage 2 . Let $\ell \in\{0,1\}$ indicate that $D$ takes the unlawful action.

(2) Observing the harm he experienced, $P$ decides whether to sue $D$. Let $s \in$ $\{0,1\}$ indicate that $P$ sues $D$.

(3) J observes whether P suffered a loss, as well as the model parameters, and updates his beliefs about the probability that $D$ is liable. $J$ then decides whether to dismiss the case or proceed to trial. Let $d \in\{0,1\}$ indicate that $\mathrm{J}$ dismisses the case. When $d=1$, the game ends. When $d=0$, the game proceeds to stage 4 .

(4) This is a non-strategic stage representing trial, including discovery and courtroom proceedings. We abstract from the details of the trial stage and for now assume simply that trial perfectly reveals whether $D$ is liable. A liable D must compensate $\mathrm{P}$ for her full loss. A not liable $\mathrm{D}$ makes no payment to $\mathrm{P}$. In addition to any compensation, trial imposes costs on $D$ and $P$, which we denote by $c_{\mathrm{D}}>0$ and $c_{\mathrm{P}}>0$.

We use $\rho$ with an action-specific subscript to denote a mixed strategy. That is, $\rho_{\ell}$ denotes the probability $\mathrm{D}$ chooses the unlawful action, $\rho_{s}$ denotes the probability $\mathrm{P}$ sues $D$, and $\rho_{d}$ denotes the probability $J$ dismisses a suit.

3.1.1. The Benefits and Harms of the Unlawful Act. We model D's choice of whether to take the liable action in stage 1 as a choice between two alternative actions, $x_{1}$ and $x_{0}$. Action $x_{1}$ provides a higher direct benefit to $\mathrm{D}$, but also imposes a negative externality on $\mathrm{P}$, for which $\mathrm{D}$ is "liable." Without loss of generality, we assume action $x_{1}$ and $x_{0}$ provides $P$ benefit $v_{1}=v>0$ and $v_{0}=0$ respectively. So $v$ represents

\footnotetext{
${ }^{7}$ The paper notes that a full-scale model of deterrence "is a daunting [task], and it is certainly beyond the scope of [his] work" (p44).
} 
the reletive benefit from the unlawful action. One may imagine that $x_{1}$ is an act of negligence (e.g., not taking reasonable safety precautions), an act that is so inherently dangerous (e.g., using dynamite) that the law makes the defendant strictly liable for all losses caused by the act, or an intentional illegal act (e.g., entering into an agreement to restrain trade). When $\mathrm{D}$ takes action $x_{1}, \mathrm{P}$ experiences a loss of value $h>0$ with probability 1 due to D's action. When D takes action $x_{0}$, he is "not liable," although P may still experience loss $h$ (e.g., one may still slip in a driveway even if the owner takes all reasonable steps to minimize ice build up on the driveway; a mine may still collapse even if the mining company used an explosive that is not inherently dangerous under the law; or there may be restraints of trade that do not violate antitrust law). Let $\eta \in(0,1)$ denote the probability that $\mathrm{P}$ experiences loss $h$ when $\mathrm{D}$ chooses $x_{0}$; with probability $1-\eta$ no loss occurs. ${ }^{8}$ Any loss suffered by $\mathrm{P}$ is publicly observed, although neither $\mathrm{P}$ nor $\mathrm{J}$ observe whether $\mathrm{D}$ is liable.

3.1.2. Trial and Discovery Process. If $P$ brings suit against $D$, and the suit is not dismissed by $\mathrm{J}$, the case moves to a trial stage in which it is publicly revealed whether $D$ is liable. The trial stage encompasses more than just the courtroom proceedings. It also captures the discovery process that takes place following a judge's decision not to dismiss a case, in which the parties have an opportunity to compel the disclosure of evidence from each other. We abstract from the details of the trial stage and for now assume simply that when $J$ does not dismiss a suit, $\ell$ is perfectly revealed because $\mathrm{J}$ has all of the relevant evidence before her. ${ }^{9}$ A suit that reaches the trial stage imposes legal costs $c_{\mathrm{P}}$ on $\mathrm{P}$ and $c_{\mathrm{D}}$ on $\mathrm{D}$, which encompass total costs of preparing for and going to trial.

3.1.3. Litigant Payoffs. Both $P$ and $D$ are concerned about payments made from $D$ to $P$ and about the cost of trial. The plaintiff and defendant earn respective payoffs

$$
u_{\mathrm{P}}=-h+s(1-d)\left(\ell h-c_{\mathrm{P}}\right), \quad \text { and } \quad u_{\mathrm{D}}=v_{\ell}-s(1-d)\left(\ell h+c_{\mathrm{D}}\right),
$$

when P suffers loss $h$, and $u_{\mathrm{P}}=0$ and $u_{\mathrm{D}}=v_{0}$ when P does not suffer loss $h$. Remember, $t=0$ when the judge dismisses the case or a trial reveals that $\mathrm{D}$ is not liable, and $t=h$ when a trial reveals $\mathrm{D}$ is liable. The value $s(1-d)$ equals 0 when $\mathrm{P}$ does not sue $\mathrm{D}$ or the suit is dismissed, and 1 when the case reaches trial.

\footnotetext{
${ }^{8}$ Assuming that loss occurs with probability 1 when $x_{1}$ simplifies the analysis, but does not drive any of the results. Similar qualitative results would hold if we alternatively assumed harm probabilities $\eta_{1}$ and $\eta_{0}$ corresponding to actions $x_{1}$ and $x_{0}$, where $0<\eta_{0}<\eta_{1}<1$, meaning that loss is more likely when $\mathrm{D}$ takes the unlawful action.

${ }^{9}$ We note that the trial stage may not, and usually cannot, perfectly reveal the liability of D because the judge is limited to the relevant evidence provided by the parties. Nevertheless, we assume that liability is "perfectly" revealed because the judge cannot consider anything more than this evidence to determine liability. Indeed, it probably does not make sense to compare the evidence at trial to perfect information because in most cases there is no way for either the parties or the judge to know what "really" happened. In Section 8, we discuss in more detail how legal error affects our results.
} 
3.1.4. Judicial Screening. Given that $P$ suffered loss $h, P$ and J form their beliefs about D's first period action. Denote these beliefs by $\mu$, where $\mu$ is the probability $\mathrm{P}$ and $\mathrm{J}$ believe $\ell=1$ given that $P$ suffered a loss. $P$ forms these beliefs after harm occurs, while $\mathrm{J}$ form these beliefs during the pleading procedure, when he is likely to be made aware of the parameter values (for $c_{D}, c_{P}, v, h, \eta$ ) which apply for the given lawsuit.

$\mathrm{J}$ dismisses a case when she believes $\mathrm{D}$ is sufficiently unlikely to be liable. Formally, there exists a threshold value $\bar{\mu} \in(0,1)$ such that $J$ dismisses a case when $\mu<\bar{\mu}$, allows the case to proceed to trial when $\bar{\mu}<\mu$, and can choose either action or to to randomize when $\mu=\bar{\mu} .^{10}$ One interpretation of $\bar{\mu}$ is that the threshold at which the social benefits of trial equal the costs. When $\mu$ is higher than this threshold, D is sufficiently likely to be liable that a trial is warranted, and when $\mu$ is lower than this threshold, the probability of trial leading to $D$ being found liable is sufficiently low that a trial is not worth the costs. ${ }^{11}$ We take a general approach to interpreting these pleading standards, solving the game for any $\bar{\mu} \in(0,1)$, and thus allowing for any underlying objective function by $\mathrm{J}$.

Because both Twombly and Iqbal increase the standard of plausibility that a lawsuit must meet before proceeding to discovery and trial, the new pleading standard can be reasonably interpreted as an increase in $\bar{\mu}$.

3.1.5. Solution Concept and Posterior Beliefs. We solve for the Perfect Bayesian Equilibrium (PBE) of the game. A description of equilibrium must define: (1) D's choice of $\rho_{\ell} ;$ (2) P's choice of $\rho_{s}$; and (4) J's choice of $\rho_{d}$. Additionally, a formal description of equilibrium should include $P$ and J's beliefs about $\ell$, given by $\mu$. In equilibrium, each player's strategy must be a best response given the strategies of the other players and the player's beliefs. Beliefs must be consistent with Bayes' Rule given the equilibrium strategies.

\footnotetext{
${ }^{10}$ It is conceivable that a pleading standard set by high court specifies that $\mathrm{J}$ take a specific action when $\mu=\bar{\mu}$. However, this does not appear to be the case when examining the language of the Twombly and Iqbal rulings, which strongly suggest that the courts engage in a cost benefit analysis when deciding whether to dismiss a lawsuit, necessarily giving $\mathrm{J}$ some discretion to dismiss (or not dismiss) in very close cases. We therefore focus on pleading standards that do not specify a tie breaking action; although considering such rules would be necessary if considering the optimal design of pleading standards, which is not a focus of our paper.

${ }^{11}$ We can explicitly write down the judge's payoff function and endogenize $\bar{\mu}$. For example, we can write J's utility as $u_{\mathrm{J}}=-(1-s(1-d)) \ell \theta h-s(1-d)\left(c_{\mathrm{P}}+c_{\mathrm{D}}\right)$, where $\theta h>0$ represents the social costs due to the inaccurate litigation outcomes, and $c_{\mathrm{P}}+c_{\mathrm{D}}$ represents the deadweight loss associated with discovery and trial costs. Dismissing a suit (so that $s(1-d)=0$ ) avoids the costs associated with trial, but also decreases the expected accuracy of the outcome. In this case, J receives expected payoff $u_{\mathrm{J}}=-\mu \theta h$, where $\mu$ is $\mathrm{J}$ 's posterior belief that $\mathrm{D}$ is liable. Conducting a trial maximizes the accuracy of litigation outcomes, but incurs litigation costs. Therefore, $J$ expects payoff $u_{J}=-\left(c_{P}+c_{D}\right)$ from allowing a case to proceed. When $\mu>\left(c_{\mathrm{P}}+c_{\mathrm{D}}\right) / \theta h$, D is sufficiently likely to be liable and the expected social benefits of trial dominate the costs. In this case, J prefers to allow a case to proceed to trial. When $\mu<\left(c_{\mathrm{P}}+c_{\mathrm{D}}\right) / \theta h$, however, the expected social benefits of trial are dominated by the costs and J prefers to dismiss the suit. In the example above, $\bar{\mu}=\left(c_{\mathrm{P}}+c_{\mathrm{D}}\right) / \theta h$.
} 
It is a requirement of Perfect Bayesian Equilibrium that equilibrium beliefs are consistent with player strategies in earlier stages of the game. In equilibrium, the posterior beliefs that $\mathrm{P}$ and $\mathrm{J}$ form about $\mathrm{D}$ 's first period action must be consistent with D's strategy $\rho_{\ell}$. The equilibrium posterior belief represented by the probability $\mathrm{D}$ is liable is therefore

$$
\mu=\operatorname{Pr}(\ell=1 \mid h)=\frac{\rho_{\ell}}{\rho_{\ell}+\eta\left(1-\rho_{\ell}\right)} .
$$

3.2. Parameter Assumptions. In order to focus the analysis on the most relevant parameter cases, we introduce two assumptions regarding D's benefit from unlawful action relative to lawful action, $v$, and P's loss from unlawful action, $h$.

First, we assume that D's benefit from unlawful action relative to lawful action is not too large:

$$
v<h+(1-\eta) c_{\mathrm{D}}
$$

When this assumption is violated, taking the unlawful action is sufficiently attractive so that $D$ always takes the unlawful action. We assume A1 to focus on litigation in which judicial screening may impact D's decision to take the unlawful action.

Second, we assume that the benefit to $P$ of going to trial against a liable defendant $\left(h-c_{\mathrm{P}}\right)$ is positive:

$$
h>c_{\mathrm{P}} .
$$

When this assumption is violated, $P$ would never sue $D$. We assume A2 to focus on litigation in which $\mathrm{J}$ may play an active role.

\section{EQUILIBRIUM}

We divide the possible equilibria into three categories. First, we consider the "full deterrence" possibility in which D always chooses action $x_{0}$. Second, we consider the "no deterrence" possibility in which $\mathrm{D}$ always chooses the unlawful action $x_{1}$. Third, we consider the "partial deterrence" possibility in which D mixes between action $x_{1}$ and $x_{0}$.

4.1. Full Deterrence Equilibrium. We can rule out the existence of a full deterrence equilibrium in which $D$ always takes the lawful action, $x_{0}$.

In a full deterrence equilibrium, $\mathrm{D}$ always takes the lawful action, $x_{0}$. J's equilibrium belief about D's liability must be consistent with $\mathrm{D}^{\prime}$ s action. In a full deterrence equilibrium, J's posterior belief is $\mu=\operatorname{Pr}(\ell=1 \mid h)=0$. This is lower than $\bar{\mu}$, so J always dismisses a lawsuit. Given J's equilibrium strategy, D anticipates payoff $v_{0}=0$ from the lawful action. When $D$ deviates to take the unlawful action, he expects payoff $v_{1}=v>0$. Therefore, $\mathrm{D}$ has an incentive to deviate to take the unlawful action and a full deterrence equilibrium does not exist. 
4.2. No Deterrence Equilibrium. We can also rule out the existence of a no deterrence equilibrium in which $D$ always takes the unlawful action, $x_{1}$.

In a no deterrence equilibrium, $\mathrm{D}$ always takes the unlawful action, $x_{1} . \mathrm{P}$ and $\mathrm{J}$ 's equilibrium beliefs about D's liability must be consistent with D's action, so their beliefs are $\mu=\operatorname{Pr}(\ell=1 \mid h)=1$ in a no deterrence equilibrium. This is higher than $\bar{\mu}$, so $\mathrm{J}$ always allows a lawsuit to proceed.

Given J's equilibrium strategy, $P$ anticipates benefits $h-c_{P}$ from bringing suit against $D$. A2 ensures $h-c_{P}>0$, so $P$ prefers to sue $D$ in a no deterrence equilibrium.

Given $P$ and J's equilibrium strategy, D anticipates payoff $v_{1}-h-c_{D}$ from the unlawful action. When $D$ deviates to take the lawful action, he expects payoff $v_{0}-$ $\eta c_{\mathrm{D}}$. In a no deterrence equilibrium, $\mathrm{D}$ must prefer to take the unlawful action rather than the lawful action. This is the case when $v_{1}-h-c_{\mathrm{D}}>v_{0}-\eta c_{\mathrm{D}}$, or equivalently $v>h+(1-\eta) c_{\mathrm{D}}$. Since this contradicts A1, a no deterrence equilibrium does not exist.

4.3. Partial Deterrence Equilibrium. Next, we consider the possibility of a partial deterrence equilibrium, where $D$ chooses the unlawful action only some of the time. There are two possible partial deterrence equilibria, depending on the value of $\bar{\mu}$.

The first possibility happens when pleading standards are sufficiently low. This is the case when

$$
\bar{\mu}<\frac{C_{\mathrm{P}}}{h} .
$$

When pleading standards are sufficiently low, J always allows lawsuits to proceed to trial. In equilibrium, D mixes in his choice of the unlawful action, taking the unlawful action just often enough to leave to leave $P$ indifferent between pursuing trial and not suing. Lemma 1 provides a formal summary of this partial deterrence equilibrium.

Lemma 1. When (1) is satisfied, there exists a partial deterrence equilibrium in which

- D's strategy: choose the unlawful action with probability

$$
\rho_{\ell}=\frac{\eta c_{P}}{h-(1-\eta) c_{P}} .
$$

- $P^{\prime}$ s strategy: bring suit against $D$ with probability

$$
\rho_{s}=\frac{v}{h+(1-\eta) c_{D}}
$$

- J's strategy: never dismiss the suit

$$
\rho_{d}=0 .
$$

- Posterior beliefs:

$$
\mu=\frac{c_{P}}{h} .
$$


A different partial deterrence equilibrium exists when the pleading standards are relatively high. This is the case when

$$
\bar{\mu} \geq \frac{c_{\mathrm{P}}}{h} .
$$

In this case, $\mathrm{J}$ dismisses a lawsuit only some of the time. The equilibrium involves $\mathrm{D}$ mixing in his choice to take the unlawful action, taking the unlawful action often enough to leave $P$ always suing $D$, and $J$ indifferent between dismissing a case and allowing a case to proceed to trial. $J$ then dismisses a case just often enough to make $\mathrm{D}$ indifferent in his choice of whether to take the unlawful action. Lemma 2 provides a formal summary of this partial deterrence equilibrium.

Lemma 2. When (2) is satisfied, there exists a partial deterrence equilibrium in which

- D's strategy: choose the unlawful action with probability

$$
\rho_{\ell}=\frac{\eta \bar{\mu}}{1-(1-\eta) \bar{\mu}} .
$$

- $P^{\prime}$ s strategy: always sues

$$
\rho_{s}=1
$$

- J's strategy: dismiss a case with probability

$$
\rho_{d}=1-\frac{v}{h+(1-\eta) c_{D}} .
$$

- Posterior beliefs:

$$
\mu=\bar{\mu} .
$$

When $\bar{\mu}=c_{\mathrm{P}} / h$, there is a continuum of partial deterrence equilibria, which differ in terms of P's strategy to sue and J's strategy to dismiss a case, but not in D's strategy to take the unlawful action which is the same in each of the equilibria. One of these equilibria is identical to the partial deterrence equilibrium that is described in Lemma 2. When discussing the impact of stronger pleading standards, we focus on this equilibrium. Assuming that a different equilibrium arrises in the case where a continuum of equilibria exists does not change our results.

\section{Impact of Stronger Pleading Standards}

The main contribution of our analysis is to study the impact of stronger pleading standards on litigation outcomes and behavior, while accounting for the fact that changes in litigation procedure will alter the incentives for potential defendants to engage in unlawful behavior in the first place. Since stronger pleading standards can be interpreted as an increase in $\bar{\mu}$ in our model, we consider the impact of an increase in $\bar{\mu}$ on deterrence, litigation costs and litigation accuracy in this section. 
5.1. Deterrence. In this section, we consider the impact of increased pleading standards on D's ex ante decision between the unlawful action $x_{1}$ and the lawful action $x_{0}$.

From Lemma 1, when $\bar{\mu}<c_{\mathrm{P}} / h$, there exists a partial deterrence equilibrium in which $\mathrm{D}$ chooses the unlawful action with probability

$$
\rho_{\ell}=\frac{\eta c_{P}}{h-(1-\eta) c_{P}} \text {. }
$$

This probability does not depend on $\bar{\mu}$. So an increase in $\bar{\mu}$ has no impact on deterrence.

From Lemma 2, when $\bar{\mu} \geq c_{\mathrm{P}} / h$, there exists a partial deterrence equilibrium in which $\mathrm{D}$ chooses the unlawful action with probability

$$
\rho_{\ell}=\frac{\eta \bar{\mu}}{1-(1-\eta) \bar{\mu}} \text {. }
$$

By inspection, this probability is increasing in $\bar{\mu}$. So a marginal increase in $\bar{\mu}$ increases the probability that $\mathrm{D}$ takes the unlawful action, decreasing deterrence.

Notice that when $\bar{\mu}=c_{\mathrm{P}} / h$, the two equilibrium values of $\rho_{\ell}$ are equal. This implies that the level of deterrence is a continuous function of $\bar{\mu}$, at first constant and then decreasing in the pleading standard.

When pleading standards are sufficiently low (when $\bar{\mu}<c_{\mathrm{P}} / h$ ), J always brings suit to trial. In this case, a marginal increase in pleading standards has no impact on behavior or deterrence. When pleading standards are relatively high (when $\left.\bar{\mu} \geq c_{\mathrm{P}} / h\right)$, J dismisses a lawsuit with positive probability, and this probability depends on the strength of the pleading standards. In this case, a marginal increase in pleading standards results in higher probability that a lawsuit is dismissed by $\mathrm{J}$. $\mathrm{D}$ anticipates higher dismissal rates associated with higher pleading standards, and chooses the unlawful action more often.

Therefore, when pleading standards are sufficiently low (when $\bar{\mu}<c_{\mathrm{P}} / h$ ), a marginal increase in pleading standards has no impact on deterrence. When pleading standards are relatively high (when $\bar{\mu} \geq c_{\mathrm{P}} / h$ ), a marginal increase in pleading standards decreases deterrence. Together, these results imply the following.

Proposition 1. Suppose the pleading standard increases from $\bar{\mu}$ to $\bar{\mu}^{\prime} \in(\bar{\mu}, 1)$. If $\bar{\mu}^{\prime} \leq c_{P} / h$, then the increase in pleading standard has no impact on deterrence. If $\bar{\mu}^{\prime}>c_{P} / h$, then the increase in pleading standard decreases deterrence.

5.2. Litigation Costs. Now we consider how stronger pleading standards affect total litigation costs. A suit that reaches the trial stage imposes legal costs on both $\mathrm{P}$ and $D$. The expected total litigation costs depend on the probability that $P$ experiences harm and the probability that a suit reaches the trial stage. Denote total litigation costs by $c$.

$$
E c=\left[\rho_{\ell} \rho_{s}\left(1-\rho_{d}\right)+\left(1-\rho_{\ell}\right) \eta \rho_{s}\left(1-\rho_{d}\right)\right]\left(c_{\mathrm{P}}+c_{\mathrm{D}}\right) .
$$


Given equilibrium strategies described in Lemma 1 and Lemma 2, we have

$$
E c= \begin{cases}\frac{\eta v h\left(c_{\mathrm{P}}+c_{\mathrm{D}}\right)}{\left(h+(1-\eta) c_{\mathrm{D}}\right)\left(h-(1-\eta) c_{\mathrm{P}}\right)} & \text { if } \bar{\mu}<c_{\mathrm{P}} / h \\ \frac{\eta v\left(c_{\mathrm{P}}+c_{\mathrm{D}}\right)}{\left(h+(1-\eta) c_{\mathrm{D}}\right)(1-(1-\eta) \bar{\mu})} & \text { if } \bar{\mu} \geq c_{\mathrm{P}} / h\end{cases}
$$

As shown in Lemma 1, when pleading standards are sufficiently low (when $\bar{\mu}<$ $\left.c_{\mathrm{P}} / h\right), \mathrm{J}$ always allows a lawsuit to proceed to discovery and trial. In this case, D's decision to take the unlawful action and P's decision to sue do not depend on $\bar{\mu}$. A marginal increase in $\bar{\mu}$ has no impact on the probability that $\mathrm{P}$ experiences harm or the probability that a suit reaches the trial stage, and therefore does not affect the expected litigation costs.

When pleading standards are relatively high (when $\bar{\mu} \geq c_{\mathrm{P}} / h$ ), D's decision to take the unlawful action depends on the strength of the pleading standards. A marginal increase in $\bar{\mu}$ incentivizes $\mathrm{D}$ to take the unlawful action more often, and therefore increases the probability that $P$ experiences harm. But the probability that a claim reaches trial is independent of the pleading standard. Therefore, stronger pleading standards increase the probability that $P$ experiences harm and a suit reaches the trial stage, resulting in higher expected litigation costs.

Therefore, when pleading standards are sufficiently low (when $\bar{\mu}<c_{\mathrm{P}} / h$ ), a marginal increase in pleading standards has no impact on total litigation costs. When pleading standards are relatively high (when $\bar{\mu} \geq c_{\mathrm{P}} / h$ ), a marginal increase in pleading standards increases total litigation costs. Together, these results imply the following.

Proposition 2. Suppose the pleading standard increases from $\bar{\mu}$ to $\bar{\mu}^{\prime} \in(\bar{\mu}, 1)$. If $\bar{\mu}^{\prime} \leq$ $c_{P} / h$, then the increase in pleading standard has no impact on expected litigation costs. If $\bar{\mu}^{\prime}>c_{P} / h$, then the increase in pleading standard increases total expected litigation costs.

In contrast to the Supreme Court's statement that higher pleading standards decrease the costs of litigation, we find that the society may spend more on litigation with higher pleading standards. This is because judicial screening causes the number of injury claims to increase, and does not alter the probability a given injury claim reaches trial.

5.3. Outcome Accuracy. Now we consider how increased pleading standards affect the expected value of $\delta \equiv|\ell h-t|$, which represents the compensation error that occurs when a liable $\mathrm{D}$ does not fully compensate $\mathrm{P}$ for her loss. 
Given equilibrium strategies described in Lemma 1 and Lemma 2, we have

$$
E \delta=\left\{\begin{array}{cl}
\frac{\eta c_{\mathrm{P}} h\left(h+(1-\eta) c_{\mathrm{D}}-v\right)}{\left(h+(1-\eta) c_{\mathrm{D}}\right)\left(h-(1-\eta) c_{\mathrm{P}}\right)} & \text { if } \bar{\mu}<c_{\mathrm{P}} / h \\
\frac{\eta \bar{\mu} h\left(\left(h+(1-\eta) c_{\mathrm{D}}\right)-v\right)}{\left(h+(1-\eta) c_{\mathrm{D}}\right)(1-(1-\eta) \bar{\mu})} & \text { if } \bar{\mu} \geq c_{\mathrm{P}} / h
\end{array}\right.
$$

As shown in Lemma 1, when pleading standards are sufficiently low (when $\bar{\mu}<$ $\left.c_{\mathrm{P}} / h\right), \mathrm{J}$ always allows a lawsuit to proceed to discovery and trial. In this case, D's decision to take the unlawful action and P's decision to sue do not depend on $\bar{\mu}$. A marginal increase in $\bar{\mu}$ has no impact on the probability that $\mathrm{P}$ experiences harm or the probability that a liable D compensates P's loss, and therefore does not affect the expected compensation error.

When pleading standards are relatively high (when $\bar{\mu} \geq c_{\mathrm{P}} / h$ ), a marginal increase in $\bar{\mu}$ incentivizes $\mathrm{D}$ to take the unlawful action more often, but has no impact on the probability that a liable D compensates P's loss. Therefore, stronger pleading standards increase the probability that $\mathrm{D}$ is liable and does not compensate $\mathrm{P}^{\prime}$ s loss. This increases the expected compensation error and reduces outcome accuracy.

Therefore, when pleading standards are sufficiently low (when $\bar{\mu}<c_{\mathrm{P}} / h$ ), a marginal increase in pleading standards has no impact on outcome accuracy. When pleading standards are relatively high (when $\bar{\mu} \geq c_{\mathrm{P}} / h$ ), a marginal increase in pleading standards decreases outcome accuracy. Together, these results imply the following.

Proposition 3. Suppose the pleading standard increases from $\bar{\mu}$ to $\bar{\mu}^{\prime} \in(\bar{\mu}, 1)$. If $\bar{\mu}^{\prime} \leq c_{P} / h$, then the increase in pleading standard has no impact on expected outcome accuracy. If $\bar{\mu}^{\prime}>c_{P} / h$, then the increase in pleading standard decreases expected outcome accuracy.

5.4. Eliminating Pleading. The analysis is primarily concerned with studying the impact that an increase in the pleading standards has on outcomes. Given we find that increasing pleading standards has detrimental effects, simultaneously increasing both illegal activity and litigation costs, it is worth discussing the possibility of eliminating pleading and the judge's ability to dismiss cases prior to discovery.

The elimination of pleading is equivalent to setting $\bar{\mu}=0$ in our framework. Just as an increase in pleading standards is never beneficial in our framework, the elimination of pleading is never harmful. It will either improve outcomes or have no impact on behavior.

In a world without pleading, a case is certain to go to trial if the plaintiff sues. This increases the incentives that a potential defendant has to avoid harming the plaintiff. In this case, illegal activity and the costs of litigation are lower than when judges hold cases to high standards of plausibility before allowing them to proceed to discovery and trial. 


\section{Extension with Nuisance Suits}

One of the primary arguments in favor of increased pleading standards is that they will decrease the prevalence of "in terrorem" or nuisance lawsuits. These are frivolous lawsuits intended to entice settlement from a likely innocent defendant who wants to avoid litigation costs.

Nuisance suits do not arise in equilibrium of our initial model. One might imagine that such suits do not arise because we abstract from settlements, ignoring the possibility that litigants might choose to settle a case prior to trial. Even if we allowed pre-trial settlements in our model, however, nuisance suits would not arise. This is due to the underlying assumption that the plaintiff in the initial model can only sue when she suffers a loss. When the plaintiff sustains harm and files a lawsuit against a defendant, the suit cannot be considered frivolous. To get nuisance suits as part of an equilibrium, the model needs to allow the plaintiff to sue a defendant despite not sustaining any harm.

In this section, we consider an alternative model which incorporates this element. We keep the initial model from Section 3 unchanged except for the assumption that the plaintiff can sue even when she sustains no harm. We define a nuisance suit as any lawsuit filed by a plaintiff who sustains no harm.

Consider the subgame after the plaintiff suffers no harm. In this case, the plaintiff receives zero payoff if she does not sue. If the plaintiff sues, the judge observes that the defendant sustains no harm and believes that the defendant is not liable (i.e. $\mu=0$ ). In this case, the judge will dismiss the suit and the plaintiff will receive payoff zero. So the plaintiff is indifferent between suing and not suing when she sustains no harm. Suppose that in equilibrium the plaintiff sues with probability $\hat{\rho}_{s} \in(0,1)$ when she sustains no harm. In equilibrium, both the plaintiff and the defendant expects zero payoff when the plaintiff experiences no harm.

After solving the subgame after the plaintiff suffers no harm, we can derive a new reduced game by replacing this subgame with the payoffs that result from this subgame. In the new reduced game, the game ends when the plaintiff experiences no harm, where both the plaintiff and the defendant receives zero payoff. This game is exactly the same as the game in Section 3, which has been solved in Section 4. Combining the results from Section 4 with the subgame equilibrium after the plaintiff suffers no harm, we have the following results.

Lemma 3. When $\bar{\mu}<\frac{c_{P}}{h}$, there exists a partial deterrence equilibrium in which

- D's strategy: choose the unlawful action with probability $\rho_{\ell}=\frac{\eta c_{P}}{h-(1-\eta) c_{P}}$.

- $P^{\prime}$ s strategy: bring suit against $D$ with probability $\hat{\rho}_{s}$ when sustaining no harm, and bring suit against $D$ with probability $\rho_{s}=\frac{v}{h+(1-\eta) c_{D}}$ when sustaining harm.

- J's strategy: always dismiss the suit $\rho_{d}=0$ when $P$ sustains no harm, and never dismiss the suit $\rho_{d}=0$ when $P$ sustains harm.

- Posterior beliefs: $\mu=\frac{c_{P}}{h}$.

When $\bar{\mu} \geq \frac{c_{P}}{h}$, there exists a partial deterrence equilibrium in which 
- D's strategy: choose the unlawful action with probability $\rho_{\ell}=\frac{\eta \bar{\mu}}{1-(1-\eta) \bar{\mu}}$.

- $P^{\prime}$ s strategy: bring suit against $D$ with probability $\hat{\rho}_{s}$ when sustaining no harm, and always sue $\rho_{s}=1$ when sustaining harm.

- J's strategy: always dismiss the suit $\rho_{d}=0$ when $P$ sustains no harm, and dismiss a case with probability $\rho_{d}=1-\frac{v}{h+(1-\eta) c_{D}}$ when P sustains harm.

- Posterior beliefs: $\mu=\bar{\mu}$.

A nuisance suit arises when the plaintiff sues despite not sustaining any harm. In equilibrium, this occurs with probability $p_{\text {nuisance }}=\left(1-\rho_{\ell}\right)(1-\eta) \hat{\rho}_{s}$, where $\left(1-\rho_{\ell}\right)(1-\eta)$ represents the probability that the defendant takes the lawful action and no harm occurs.

Given equilibrium strategies described in Lemma 3, we have

$$
p_{\text {nuisance }}=\left\{\begin{array}{cl}
\frac{\left(h-c_{\mathrm{P}}\right)(1-\eta) \hat{\rho}_{\mathrm{s}}}{h-(1-\eta) c_{\mathrm{P}}} & \text { if } \bar{\mu}<c_{\mathrm{P}} / h \\
\frac{(1-\bar{\mu})(1-\eta) \hat{\rho}_{s}}{1-(1-\eta) \bar{\mu}} & \text { if } \bar{\mu} \geq c_{\mathrm{P}} / h
\end{array}\right.
$$

As shown above, when $\bar{\mu}<c_{\mathrm{P}} / h$, the probability of a nuisance suit does not depend on $\bar{\mu}$. A marginal increase in $\bar{\mu}$ thus has no impact on the probability that a nuisance suit arises in equilibrium. When $\bar{\mu} \geq c_{\mathrm{P}} / h$, D's decision to take the unlawful action depends on the strength of the pleading standards. A marginal increase in $\bar{\mu}$ incentivizes $\mathrm{D}$ to take the unlawful action more often, and therefore increases the probability that $P$ experiences harm. When $P$ experiences harm and files suit against a defendant, the suit cannot be considered frivolous. Therefore, stronger pleading standards decreases the probability that a nuisance suit arises in equilibrium. This captures the intuition for the Supreme Court's argument that high litigation costs are leading to nuisance suits, and that increasing pleading standards can decreases the prevalence of such suits.

However, our results show that deterring nuisance suits is not the only effect of an increase in pleading standards. As $\bar{\mu}$ increases, equilibrium $\rho_{\ell}$ also increases when $\bar{\mu} \geq c_{\mathrm{P}} / h$. Therefore, even in the model where nuisance suits exists, increasing the pleading standard decreases deterrence. We can also verify that total litigation costs is increasing $\bar{\mu}$ when $\bar{\mu} \geq c_{\mathrm{P}} / h$. This is because judicial screening causes the number of injury claims to increase, and does not alter the probability a given injury claim reaches trial.

Proposition 4. Suppose the pleading standard increases from $\bar{\mu}$ to $\bar{\mu}^{\prime} \in(\bar{\mu}, 1)$ in the model with nuisance suits. If $\bar{\mu}^{\prime} \leq c_{P} / h$, then the increase in pleading standard has no impact on deterrence, total litigation costs or nuisance suits. If $\bar{\mu}^{\prime}>c_{P} / h$, then the increase in pleading standard decreases deterrence, increases total litigation costs and reduces nuisance suits. 
Given the deterrence effects of increasing pleading standards, our results suggest that alternative procedural mechanisms that decrease nuisance suits without decreasing deterrence may dominate an increase in the pleading standard. Alternative possibilities include committing the parties to liability determinations by the judge, such as barring settlement between the parties prior to trial, or mandating motions for summary judgment (Rosenberg and Shavell 2006, Kozel and Rosenberg 2004).

The analysis in this section illustrates how increasing pleading standards can simultaneously decrease the prevalence of nuisance suits and increase illegal activity. Considering the tradeoff between these positive and negative effects is beyond the scope of the current paper. Doing so requires a more detailed consideration of the real world distribution of the parameters at the heart of the model, which may allow one to further compare the trade off between the benefits and costs. At a minimum, the current analysis highlight how increasing pleading standards cannot be done at zero costs, and that there are deterrence effects which should be taken into account to assessing judicial procedure.

\section{Extension with “Chilling” EfFects}

The previous model focuses on a setting in which deterring defendants from a potentially harmful activity is optimal. Absent from the analysis is any notion of a "chilling" effect, where the threat of lawsuits leads a potential defendant to take an overly safe action from the perspective of social welfare. For example, a company may not choose efficient, procompetitive behavior for fear of being sued (promotional product pricing may look like predation), and a physician who worries about false positives may deny treating high-risk patients (Kaplow 2011). In such an alternative setting, judicial screening may be beneficial if it encourages more risky (but socially optimal) behavior. In such situations, the pleading standard effectively becomes the new liability rule (see Easterbrook 1989). This is another potential benefit of judicial screening that is absent from our main model, which could help offset the negative effects of increased pleading standards.

In this section, we consider an extension with "chilling" effects. In particular, we consider an alternative model with an initial stage in which $D$ decides whether to choose an overly safe action, $x_{s}$. This action does not result in harm for the plaintiff, and provides the defendant immunity from being sued. For example, a company cannot be sued for anti-competitive behavior if it does not enter the market, and a physician cannot be sued for malpractice if he refuses to treat patients. When $D$ chooses the overly safe action $x_{s}$ in the first stage, the game ends and $\mathrm{D}$ receives payoff $v_{s}$, which is less than $v_{0}$, D's payoff from choosing the lawful action $x_{0}{ }^{12}$ When $\mathrm{D}$ forgoes action $x_{s}$, the game proceeds to the game described in Section 3.1, in which $\mathrm{D}$ chooses between the lawful action, $x_{0}$, and the unlawful action, $x_{1}$. The

\footnotetext{
${ }^{12}$ Since we assume $v_{0}=0$ in the main model, $v_{s}<v_{0}$ implies that $v_{s}<0$. The assumption that $v_{0}=0$ simplifies the exposition of the paper, but is not necessary for our results. As long as $v_{s}<v_{0}<v_{1}$, the qualitative results hold.
} 
plaintiff can perfectly observe whether the defendant chooses the overly safe action $x_{s}$, but he doesn't know whether the defendant takes action $x_{0}$ or $x_{1}$ in stage two. This is consistent with the fact that it is easy to observe whether a company enters the market or a doctor treats a patient, but it is fairly difficult to observe whether a company engages in anti-competitive behavior or a doctor takes enough care when treating patients. ${ }^{13}$

In the subgame after the defendant forgoes action $x_{s}$, there are two subgame equilibria, depending on the strength of the pleading standard (see Lemma 1 and Lemma 2). In the Appendix, we show that in both equilibria, the defendant expects payoff

$$
-\frac{\eta v c_{D}}{h+(1-\eta) c_{D}} \text {. }
$$

In the first stage of the game, the defendant chooses the overly safe action $x_{s}$ when his payoff from action $x_{s}$ is higher than his expected payoff from forgoing action $x_{s}$. This is the case when

$$
\frac{\eta v c_{D}}{h+(1-\eta) c_{D}}<v_{s}
$$

As shown in (3), the range of parameter values such that D prefers to chill is independent of $\bar{\mu}$. This implies that increasing pleading standards do not change the defendant's expected payoff from taking action $x_{0}$ or $x_{1}$, and therefore does not change his incentive to take the overly safe action.

As the pleading standard becomes stronger, the defendant chooses the illegal action more often in his mixed strategy. This would be beneficial for D if the the likelihood that a liable D compensates P did not change as well. However, with higher pleading standard, $\mathrm{P}$ experiences harm more often, and the probability that a claim reaches trial is independent of the pleading standard. Therefore, stronger pleading standards increase the probability that $\mathrm{P}$ experiences harm and a suit reaches the trial stage, making it more likely for a liable D to compensate P. This increased costs from a higher probability of being forced to compensate $\mathrm{P}$ exactly offsets the increased benefit of engaging in the illegal activity more often (i.e. of facing a stronger pleading standard). Equilibrium payoffs to D, as a result of these offsetting effects, do not change with the pleading standard. As a result, the incentives for chilling also remain constant in the pleading standard.

When (3) is not satisfied, the defendant prefers to forgo the overly safe action in the first stage. In this case, the new model has the same equilibrium outcomes as in the main model, and an increase in pleading standards tends to increase illegal activity, and total expected litigation costs.

Proposition 5. In the model with "chilling" effects, increasing pleading standards

- has no impact on the range of parameter values for which D prefers to choose the overly safe action;

\footnotetext{
${ }^{13}$ Assuming that the overly safe action is unobservable does not change the qualitative results. As long as the overly safe action removes the probability of harm, then whenever harm occurs (the only interesting case in the game without nuisance suits), the plaintiff knows that the defendant didn't take the overly safe action.
} 
- tends to increase illegal activity and expected litigation costs when (3) is not satisfied, and otherwise has no impact on illegal activity, or expected litigation costs.

\section{Alternative Assumptions}

In the previous sections, we extend the model to allow for settlement, nuisance suits, and "chilling" effects. In this section, we discuss other simplifying assumptions that we made in the model, and whether relaxing them is likely to affect our results.

8.1. Imperfect trial outcomes. In the above analysis, we consider an environment in which trials perfectly reveal defendant liability. This means that a defendant, aware of his own liability, can perfectly predict trial outcomes. This assumption greatly simplifies the analysis and exposition of the paper. Relaxing this assumption does not change the qualitative results.

In unreported analysis, we solve the game assuming that trials result in the wrong outcome with positive probability. The effect of increased pleading standards on deterrence, litigation costs and litigation accuracy does not change as long as wrong outcomes do not happen too often.

8.2. Summary judgements. We also abstract from summary judgment procedures, which permit a party to avoid trial if she "shows that there is no genuine dispute as to any material fact and the [she] is entitled to judgment as a matter of law." (Fed. R. Civ. P. 56(a)). Summary judgment procedures, like pleading standards, are used by courts so that "factually insufficient claims or defenses c[an] be isolated and prevented from going to trial with the attendant unwarranted consumption of public and private resources." (See Celotex Corp. v. Catrett, 477 U.S. 317, 327 (1986) (discussing both motions to dismiss and motions for summary judgment)).

Abstracting away from summary judgment does not materially affect our analysis. Motions for summary judgment, unlike the motions to dismiss at the pleading stage, cannot be based on the allegations in pleading alone. Instead, a party seeking summary judgment show that the evidence would not allow the other side to prevail at trial. As a result, motions for summary judgment can only be asserted after both sides have had sufficient discovery to support their claims and defenses. (See Fed. R. Civ. P. 56(d)).

Moreover, the "plausibility" standard articulated by the Court in Twombly was primarily derived from the summary judgment standard of "plausibility" used in antitrust cases. See (Twombly, 550 U.S. at 555 (citing Matsushita Elec. Indus. Co. v. Zenith Radio Corp., 475 U.S. 574 (1986)). Accordingly, any lawsuit that survives dismissal under the plausibility standard articulated in Twombly would very likely also survive a summary judgment motion (Thomas 2010). The only way a motion for summary judgment would be granted is if additional discovery was conducted and a party unearthed new evidence which would support the motion. In other 
words, the effective use of summary judgment to get rid of a nondismissed case would necessarily entail some costly discovery.

Because motions for summary judgment only reduce costs, and do not eliminate them, we abstract from them because they do not undermine the assumption in the analysis that the trial and discovery process imposes costs on both parties.

\section{Conclusion}

In Bell Atlantic Corp. v. Twombly (550 U.S. 544 [2007]) and Ashcroft v. Iqbal (556 U.S. 662, 684 [2009]), the U.S. Supreme Court increased the standard of plausibility that lawsuits must meet before being allowed by a judge to proceed to discovery and trial. The Court has concluded that stronger pleading standards are necessary to reduce the number of unnecessary lawsuits, decrease total costs of litigation, and improve outcome accuracy. Although these claims are true in a setting in which the unlawful behavior of defendants is taken as given, our analysis shows how the conclusions may be reversed when potential defendants can adjust their unlawful behavior in response to changes in the litigation environment. When we account for deterrence effects, stronger pleading standards lead to the dismissal of weaker cases which would otherwise proceed to trial, which in turn incentivizes potential defendants to take unlawful actions more often. In this way, stronger pleading standards decrease deterrence, increasing the amount of unlawful activity. This can lead to the simultaneous increase in total litigation costs and decrease in outcome accuracy. With deterrence effects, our model finds that increased pleading standards tend to have the opposite effects as argued by the Supreme Court.

Our results do not rule out the possibility that stronger pleading standards provides benefits in some situations. In Section 6, we show that stronger pleading standards may decrease the prevalence of pure nuisance suits where plaintiffs sue despite of not sustaining harm. In that setting, we show how stronger pleading standards simultaneously decrease the prevalence of nuisance suits, and increases illegal activity and total litigation costs. Because of this, our contribution should be seen as highlighting a previously unrecognized cost of increasing pleading standards, which exists along side the previously recognized benefits. Our results emphasize the importance of accounting for deterrence effects when considering changes to judicial procedure. 


\section{Appendix A. Mathematical Appendix}

A.1. Proof of Lemma 1. In this section, we consider a partial deterrence equilibrium in which $J$ never dismisses a lawsuit. We first show that in such a partial deterrence equilibrium, $P$ must play mixed strategies.

Suppose that $P$ always sues $D$ after he experiences harm. In this case, $D$ expects payoff $v_{1}-h-c_{\mathrm{D}}=v-h-c_{\mathrm{D}}$ from the unlawful action, and expects payoff $v_{0}-$ $\eta c_{\mathrm{D}}=-\eta c_{\mathrm{D}}$ from the lawful action. A1 implies that $v-h-c_{\mathrm{D}}<-\eta c_{\mathrm{D}}$, so D prefers to always take the lawful action. This contradicts that $D$ plays mixed strategies in a partial deterrence equilibrium.

Suppose that $\mathrm{P}$ never sues $\mathrm{D}$. In this case, $\mathrm{D}$ expects payoff $v_{1}=v>0$ from the unlawful action, and expects payoff $v_{0}=0$ from the lawful action. Since $v_{1}>v_{0}$, $\mathrm{D}$ prefers to always take the unlawful action. This contradicts that $\mathrm{D}$ plays mixed strategies in a partial deterrence equilibrium.

We have ruled out the possibility that $P$ plays mixed strategies in a partial deterrence equilibrium. Now let's suppose that $D$ takes the unlawful action with probability $\rho_{\ell}$, and $\mathrm{P}$ sues $\mathrm{D}$ with probability $\rho_{s}$. After experiencing harm $h, \mathrm{P}$ is indifferent between suing and not suing when

$$
\frac{\rho_{\ell}}{\rho_{\ell}+\eta\left(1-\rho_{\ell}\right)} h-c_{\mathrm{P}}-h=-h .
$$

The left hand side of the above equation represents P's expected payoff from suing, while the right hand side of the above equation equals his expected payoff from not suing. Solving this equation, we have D's equilibrium strategy

$$
\rho_{\ell}=\frac{\eta c_{\mathrm{P}}}{h-(1-\eta) c_{\mathrm{P}}} \text {. }
$$

A2 ensures $\rho_{\ell}$ is between 0 and 1 .

$\mathrm{D}$ expects payoff $v_{1}-\rho_{s}\left(h+c_{\mathrm{D}}\right)=v-\rho_{s}\left(h+c_{\mathrm{D}}\right)$ from the unlawful action, and anticipates payoff $v_{0}-\eta \rho_{s} \mathcal{C}_{\mathrm{D}}=-\eta \rho_{s} \mathcal{C}_{\mathrm{D}}$ from the lawful action. In a partial deterrence equilibrium, $\mathrm{D}$ is indifferent between the unlawful action and the lawful action. This is the case when

$$
v-\rho_{s}\left(h+c_{\mathrm{D}}\right)=-\eta \rho_{s} c_{\mathrm{D}} .
$$

Solving this equation, we have $\mathrm{P}^{\prime} \mathrm{s}$ equilibrium strategy

$$
\rho_{s}=\frac{v}{h+(1-\eta) c_{D}} .
$$

A1 ensures $\rho_{s}$ is between 0 and 1 .

It remains to show that $J$ prefers to always bring a case to trial. Given D's equilibrium strategy $\rho_{\ell}, \mathrm{P}$ and J's posterior belief is

$$
\mu=\frac{\rho_{\ell}}{\rho_{\ell}+\eta\left(1-\rho_{\ell}\right)}=\frac{c_{\mathrm{P}}}{h} .
$$


$\mathrm{J}$ prefers to bring a lawsuit to trial when she believes $\mathrm{D}$ is very likely to be liable. This is the case when

$$
\bar{\mu}<\frac{c_{\mathrm{P}}}{h} .
$$

When this condition is satisfied, there exists a partial deterrence equilibrium in which $J$ always brings a case to trial, and $D$ and $P$ play the strategies specified above.

A.2. Proof of Lemma 2. In this section, we consider a partial deterrence equilibrium in which $\mathrm{J}$ dismisses a lawsuit with probability $\rho_{d}$. Suppose that in equilibrium $D$ takes the unlawful action with probability $\rho_{\ell}$. Given D's equilibrium strategy $\rho_{\ell}, \mathrm{P}$ and J's posterior beliefs are

$$
\mu=\frac{\rho_{\ell}}{\rho_{\ell}+\eta\left(1-\rho_{\ell}\right)} .
$$

$\mathrm{J}$ is indifferent between trying and dismissing a case when $\mu=\bar{\mu}$, or equivalently

$$
\frac{\rho_{\ell}}{\rho_{\ell}+\left(1-\rho_{\ell}\right) \eta}=\bar{\mu} .
$$

Solving for $\rho_{\ell}$, we have D's equilibrium strategy

$$
\rho_{\ell}=\frac{\eta \bar{\mu}}{1-(1-\eta) \bar{\mu}} \text {. }
$$

Given D's equilibrium strategy, P's expected benefit from suing D is

$$
\bar{\mu} h-c_{\mathrm{P}} .
$$

When $\bar{\mu} h-c_{\mathrm{P}}<0$ or equivalently $\bar{\mu}<c_{\mathrm{P}} / h$, P prefers not to sue D . Given $\mathrm{P}^{\prime} \mathrm{s}$ strategy, $\mathrm{D}$ anticipates payoff $v_{1}=v>0$ from the unlawful action, and anticipates payoff $v_{0}=0$ from the lawful action. Therefore, $\mathrm{D}$ prefers to always take the unlawful action. This contradicts that $\mathrm{D}$ mixes between action $x_{1}$ and $x_{0}$ in a partial deterrence equilibrium. So we don't have a partial deterrence equilibrium when $\bar{\mu}<c_{\mathrm{P}} / h$.

When $\bar{\mu} h-c_{\mathrm{P}}>0$ or equivalently $\bar{\mu}>c_{\mathrm{P}} / h, \mathrm{P}$ prefers to sue $\mathrm{D}$. Given $\mathrm{P}$ and J's strategy, D expects payoff $v_{1}-\left(1-\rho_{d}\right)\left(h+c_{\mathrm{D}}\right)=v-\left(1-\rho_{d}\right)\left(h+c_{\mathrm{D}}\right)$ from the unlawful action, and anticipates payoff $v_{0}-\eta\left(1-\rho_{d}\right) c_{\mathrm{D}}=-\eta\left(1-\rho_{d}\right) c_{\mathrm{D}}$ from the lawful action. In a partial deterrence equilibrium, $D$ is indifferent between the unlawful action and the lawful action. This is the case when

$$
v-\left(1-\rho_{d}\right)\left(h+c_{\mathrm{D}}\right)=-\eta\left(1-\rho_{d}\right) c_{\mathrm{D}} .
$$

Solving this equation, we have $J$ 's equilibrium strategy

$$
\rho_{d}=1-\frac{v}{h+(1-\eta) c_{\mathrm{D}}} .
$$

A1 ensures that $\rho_{d}$ is between 0 and 1 . Therefore, when $\bar{\mu}>c_{\mathrm{P}} / h$, we have a partial deterrence equilibrium in which $D$ takes the unlawful action with probability $\rho_{\ell}=\frac{\eta \bar{\mu}}{1-(1-\eta) \bar{\mu}}$, P sues with probability 1 , and $J$ dismisses a case with probability $\rho_{d}=1-\frac{v}{h+(1-\eta) c_{\mathrm{D}}}$. 
When $\bar{\mu} h-c_{\mathrm{P}}=0$ or equivalently $\bar{\mu}=c_{\mathrm{P}} / h, \mathrm{P}$ is indifferent between suing and not suing $D$. Suppose $P$ sues $D$ with probability $\rho_{s}$. Given $P$ and J's strategy, D expects payoff $v_{1}-\rho_{s}\left(1-\rho_{d}\right)\left(h+c_{\mathrm{D}}\right)=v-\rho_{s}\left(1-\rho_{d}\right)\left(h+c_{\mathrm{D}}\right)$ from the unlawful action, and anticipates payoff $v_{0}-\eta \rho_{s}\left(1-\rho_{d}\right) c_{\mathrm{D}}=-\eta \rho_{s}\left(1-\rho_{d}\right) c_{\mathrm{D}}$ from the lawful action. In a partial deterrence equilibrium, $D$ is indifferent between the unlawful action and the lawful action. This is the case when

$$
v-\rho_{s}\left(1-\rho_{d}\right)\left(h+c_{D}\right)=-\eta \rho_{s}\left(1-\rho_{d}\right) c_{D}
$$

Solving this equation, we have

$$
\rho_{s}\left(1-\rho_{d}\right)=\frac{v}{h+(1-\eta) c_{\mathrm{D}}} .
$$

A1 ensures that $\rho_{s}\left(1-\rho_{d}\right)$ is between 0 and 1 . Therefore, when $\bar{\mu}=c_{\mathrm{P}} / h$, we have a continuum of partial deterrence equilibria in which $D$ takes the unlawful action with probability $\rho_{\ell}=\frac{\eta \bar{\mu}}{1-(1-\eta) \bar{\mu}}$, P sues with probability $\rho_{s}$, and $\mathrm{J}$ dismisses a case with probability $\rho_{d}$. In this equilibrium, $\rho_{s}$ and $\rho_{d}$ must satisfy $\rho_{s}\left(1-\rho_{d}\right)=\frac{v}{h+(1-\eta) c_{D}}$.

A.3. Extension with "Chilling" Effects. In the subgame after the defendant forgoes action $x_{s}$, there are two subgame equilibria, depending on the strength of the pleading standard (see Lemma 1 and Lemma 2). Now we derive the defendant's expected payoff in both equilibria.

From Lemma 1, we know that when (1) is satisfied, there exists a partial deterrence equilibrium in which $D$ chooses the unlawful action with probability $\rho_{\ell}=\frac{\eta c_{P}}{h-(1-\eta) c_{P}}$, $P$ brings suit against $D$ with probability $\rho_{s}=\frac{v}{h+(1-\eta) c_{D}}$, and $\mathrm{J}$ never dismisses the suit $\left(\rho_{d}=0\right)$. In this case, D's expected payoff

$$
\begin{aligned}
E u_{\mathrm{D}} & =\rho_{\ell}\left(v-\rho_{s}\left(h+c_{\mathrm{D}}\right)-\left(1-\rho_{\ell}\right) \eta \rho_{s} c_{\mathrm{D}}\right. \\
& =-\frac{\eta v c_{\mathrm{D}}}{h+(1-\eta) c_{\mathrm{D}}} .
\end{aligned}
$$

From Lemma 2, we know that when (2) is satisfied, there exists another partial deterrence equilibrium in which $D$ chooses the unlawful action with probability $\rho_{\ell}=$ $\frac{\eta \bar{\mu}}{1-(1-\eta) \bar{\mu}}, \mathrm{P}$ brings suit against $\mathrm{D}$ with probability $\rho_{s}=1$, and $\mathrm{J}$ dismisses a case with probability $\rho_{d}=1-\frac{v}{h+(1-\eta) c_{D}}$. In this case, D's expected payoff

$$
\begin{aligned}
E u_{\mathrm{D}} & =\rho_{\ell}\left(v-\left(1-\rho_{d}\right)\left(h+c_{\mathrm{D}}\right)-\left(1-\rho_{\ell}\right) \eta\left(1-\rho_{d}\right) c_{\mathrm{D}}\right. \\
& =-\frac{\eta v c_{\mathrm{D}}}{h+(1-\eta) c_{\mathrm{D}}} .
\end{aligned}
$$




\section{REFERENCES}

Anderson, Mark, and Max Huffman. 2010. "Iqbal, Twombly, and the Expected Cost of False Positive Error." Cornell Journal of Law and Public Policy, 20(1): 1-66.

Baker, Scott, and Anup Malani. 2014. "Trial Court Budgets, the Enforcer's Dilemma, and the Rule of Law." University of Illinois Law Review, 2014: 1573-1602.

Becker, Gary S. 1968. "Crime and Punishment: An Economic Approach." Journal of Political Economy, 76(2): 169-217.

Daughety, Andrew F., and Jennifer F. Reinganum. 2013. "Cumulative Harm, Products Liability, and Bilateral Care." American Law and Economics Review, 15(2): 409442.

Daughety, Andrew F., and Jennifer F. Reinganum. 2014. "Cumulative Harm and Resilient Liability Rules for Product Markets." Journal of Law, Economics E Organization, forthcoming.

Dodson, Scott. 2010. "New Pleading, New Discovery." Michigan Law Review, 109(1): 53-90.

Dodson, Scott. 2013. New Pleading in the Twenty-First Century: Slamming the Federal Courthouse Doors? Oxford University Press.

Easterbrook, Frank H. 1989. "Discovery as Abuse." Boston University Law Review, 69(3): 635-648.

Engstrom, David Freeman. 2013. “The 'Twiqbal' Puzzle and Empirical Study of Civil Procedure." Standford Law Review, 65(6): 1203-1248.

Fitzpatrick, Brian T. 2012. "Twombly and Iqbal Reconsidered." Notre Dame Law Review, 87(4): 1621-1646.

Friedman, Ezra, and Abraham L. Wickelgren. 2006. "Bayesian Juries and The Limits to Deterrence." Journal of Law, Economics E Organization, 22(1): 70-86.

Garoupa, Nuno. 1997. "The Theory of Optimal Law Enforcement." Journal of Economic Surveys, 11(3): 267-295.

Gelbach, Jonah B. 2011. "Locking the Door to Discovery-Assessing the Effects of Twombly and Iqbal on Access to Discovery." Yale Law Journal, 121: 2270-2348.

Gelbach, Jonah B. 2012. "Selection in Motion: A Formal Model of Rule 12(B)(6) and the Twombly-Iqbal Shift in Pleading Policy." SSRN Scholarly Paper 2138428.

Hartnett, Edward A. 2009. "Taming Twombly, Even after Iqbal." University of Pennsylvania Law Review, 158(2): 473-516.

Hoffman, Lonny. 2011. "Twombly and Iqbal's Measure: An Assessment of the Federal Judicial Center's Study of Motions to Dismiss." Federal Courts Law Review, 6(1): 1-36.

Huston, Michael R. 2010. "Pleading with Congress to Resist the Urge to Overrule Twombly and Iqbal." Michigan Law Review, 109(3): 415-445.

Hylton, Keith N. 1990. "The Influence of Litigation Costs on Deterrence under Strict Liability and under Negligence." International Review of Law and Economics, 10: 161171.

Hylton, Keith N. 1993. "Litigation Cost Allocation Rules and Compliance with the Negligence Standard." Journal of Legal Studies, 22(2): 457-476. 
Jost, Peter J. 1995. "Disclosure of Information and Incentives for Care." International Review of Law and Economics, 15(1): 65-85.

Kaplow, Louis. 2011. "On the Optimal Burden of Proof." Journal of Political Economy, 119(6): 1104-1140.

Kaplow, Louis. 2012. “Optimal Multistage Adjudication.” Available at SSRN 1983519. unpublished working paper.

Kaplow, Louis. 2013. "Multistage Adjudication." Harvard Law Review, 126(5): 1179 1298.

Kozel, Randy J., and David Rosenberg. 2004. "Solving the Nuisance-Value Settlement Problem: Manadatory Summary Judgment." Virginia Law Review, 90(7): 1849-1907.

Landeo, Claudia M., Maxim Nikitin, and Scott Baker. 2007. "Deterrence, Lawsuits, and Litigation Outcomes Under Court Errors." Journal of Law, Economics E Organization, 23(1): 57-97.

Miller, Arthur R. 2010. "From Conley to Twombly to Iqbal: A Double Play on the Federal Rules of Civil Procedure." Duke law Journal, 60(1): 1-130.

Ordover, Janusz A. 1978. "Costly Litigation in the Model of Single Activity Accidents." Journal of Legal Studies, 7(2): 243-261.

Png, I.P.L. 1987. "Litigation, Liability, and Incentives for Care." Journal of Public Economics, 34(1): 61-85.

Polinsky, A. Mitchell, and Steven Shavell. 2000. "The Economic Theory of Public Enforcement of Law." Journal of Economic Literature, 38(1): 45-76.

Polinsky, A. Mitchell, and Yeon-Koo Che. 1991. "Decoupling Liability: Optimal Incentives for Care and Litigation." RAND Journal of Economics, 22(4): 562-570.

Reinert, Alex. 2012. "Pleading as Information-forcing." Law and Contemporary Problems, 75(1): 1-35.

Rosenberg, David, and Steven Shavell. 2006. "A Solution to the Problem of Nuisance Suits: The Option to Have the Court Bar Settlement." International Review of Law and Economics, 26(1): 42-51.

Rowe, Jr., Thomas D. 1982. “The Legal Theory of Attorney Fee Shifting: A Critical Overview." Duke Law Journal, 4: 651-680.

Spencer, A. Benjamin. 2013. "Pleading and Access to Civil Justice: A Response to Twiqbal Apologists." UCLA Law Review, 60: 1710-1739.

Steinman, Adam. 2010. “The Pleading Problem." Stanford Law Review, 62(5): 12931360.

Thomas, Suja A. 2010. "The New Summary Judgment Motion: The Motion to Dismiss Under Iqbal and Twombly." Lewis E Clark Law Review, 14(15-42).

Wijck, Peter Van, and Ben Van Velthoven. 2000. "An Economic Analysis of the American and the Continental Rule for Allocating Legal Costs." European Journal of Law and Economics, 9(2): 115-125. 